\title{
POACHING IN THE JIPE AREA OF THE TSAVO ROYAL NATIONAL PARK, KENYA
}

By Peter Jenkins, Assistant Warden.

(From a report made to the Trustecs of the Royal National Parks of Kenya and published with permission)

This report is based on two and a half months' work along the western boundary of the park from Ziwani to Lake Jipe and in the adjoining area.

The Poachers.-The tribes reponsible for the poaching in this area are : NItaveta, Wakamba, Wapore, Wanyasa, Teita. These people are found along the entire western boundary of the Jipe area. During eight months of the year there is not a drop of water inside this part of the park, and every animal must leave it to drink. Poachers are then able to kill game on their doorsteps with little danger of being caught, and the meat can be cut up and removed at once leaving no trace. During the rains, when waterholes are full and game scattered, small gangs operate far afield into the park.

Poachers hunt with snares and poisoned arrows. Bush fences are constructed, some several miles in length, covering the approaches to water. Gaps are left approximately every twenty yards and set in these gaps are snares of wire cable. In some places two snares cover every gap, one set low enough to catch animals the size of zebra and kongoni, the other, of stout $\frac{1}{4}$ in. bull-dozer winch cable stolen from the surrounding estates, is set high enough for giraffe. Often these snares are laid-sometimes miles of them-and not visited again for weeks, if ever. The animals, if caught by the neck, die of suffocation, or of starvation and thirst if caught by the leg. Skeletons have been found of game caught in snares months before and left to die a slow and lingering death. A common practice of hunters who have caught more animals than they can carry away dead is to ham-string the others. This ensures these cannot escape but stay alive for several days so that the meat is kept fresh.

Hides where bowmen can lie during the day or on moonlight nights can be found covering all water points and salt licks. Much of the poison used is old or of inferior quality and a number of animals escape and die later many miles away, never to be recovered. Last month my scouts found three giraffe, two rhinoceros and several zebra which had thus died.

Pits are used by the Teita in the Naktau/Bura area.

Disposal of Meat and Trophies.-Giraffe are killed in large 


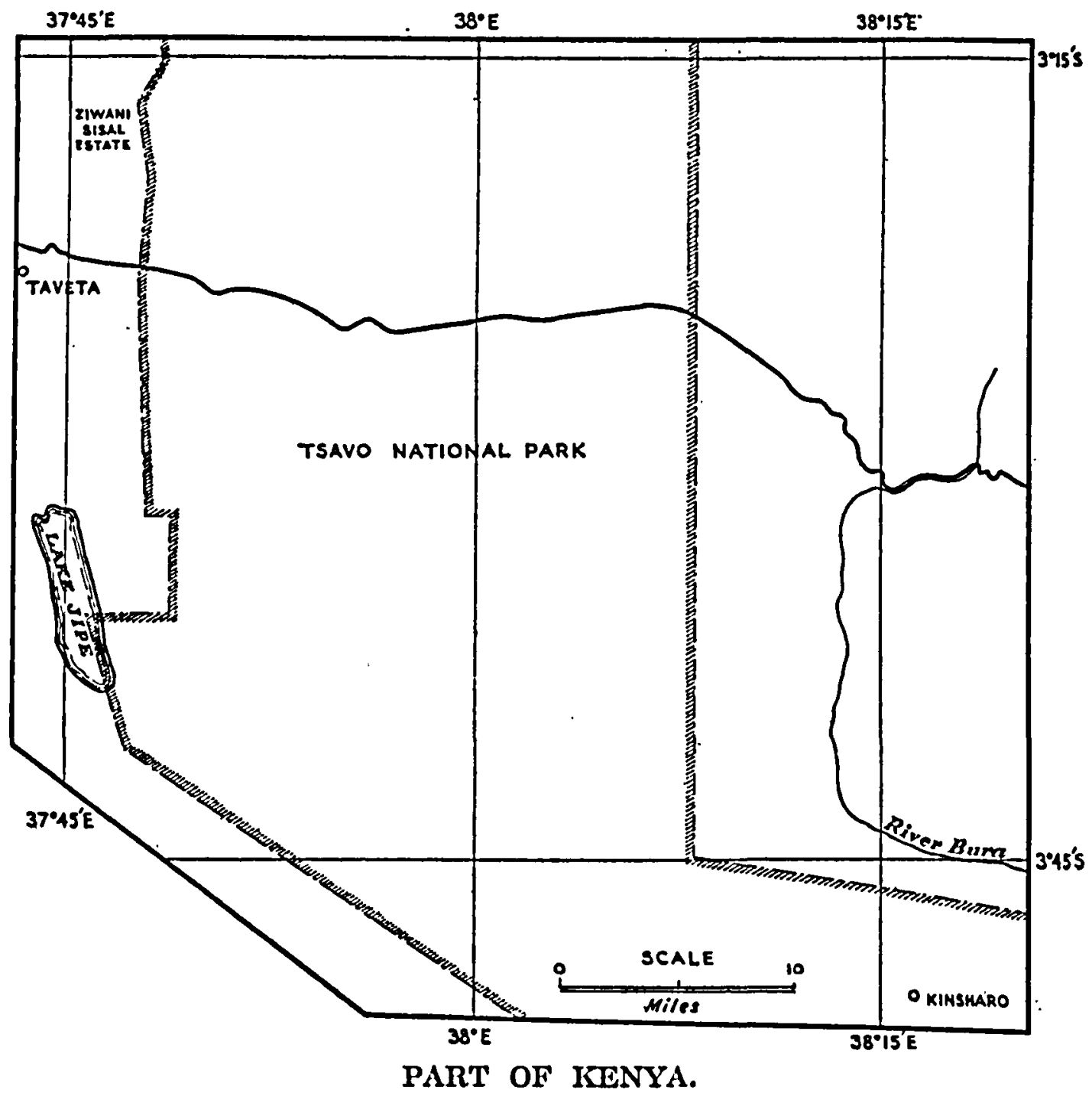

numbers-they are easy to kill, produce a large quantity of meat and sinew from which bow strings are made. The meat is cut into strips and sold either fresh or dried-prices vary between $1 s$. and $2 s$. for one arm's length of meat (measured by the length of a man's arm). Skins are rarely brought in as they would produce incriminating evidence; they are left in the bush for the hyænas. The meat is not taken into the huts-it is cut and sold in the bush, and a man buying meat will hide it in some convenient spot near his house. Bows and arrows are usually hidden away in the bush so that in the event of a raid nothing can be found.

Prosecution.-Owing to the necessity of producing exhibits in court, conviction of these people is extremely difficult. Recently, in eleven convictions only detention camp imprisonment was imposed, which type of imprisonment is no deterrent at all. $A$ 
typical case was that of a poison dealer. He was charged with being in possession of fifty-four bundles of arrow poison, of selling arrow poison (Acokanthera) and of being in illegal possession of one lesser kudu skin, one waterbuck skin and one giraffe tail. For being in possession of the poison, he received a 350s. fine or 6 weeks' detention camp, and for illegal possession of game trophies a 200s. fine or six wecks' detention camp.

One man pleaded guilty to killing four giraffe in snares this year-he said that he had put up twenty snares at a time for giraffe. Eighty-four snares were recovered in an area of approximately one mile long by one mile wide. Three places were seen where giraffe had recently been killed and cut up. Of the bigger game, it is mainly rhino that are killed-an Indian trader at Himo is paying $18 s$. per lb. for the horn.

Acolanthera Poison.-Acokanthera is the name of a tree which forms the main ingredient of most of the arrow poison used in Kenya. Its full name is Acokanthera fricsiorum and it looks rather like a stunted Italian olive. It bears a small berry which turns red when ripe, and strangely enough, makes quite a good edible jam. The poison is prepared by boiling the branches and roots, but only those taken from a selected tree, for it is not all acokanthera which yield the poison. Those which are potent can generally be identified by having a number of dead creatures at their base, including rodents and insects. It is a common tree, although those with really good poison are not by any means plentiful.

This acokanthera poison is brought into the Jipe area by Giriama or Teita poison scllers in bundles about the size of a loaf of bread, hidden in a suitcase or basket. It is then broken into small packets, wrapped in dried maize leaves for protection. One packet is just enough poison for one arrow and sells at 50 cents a packet. On the 16th November, 1955, a Giriama poison seller was arrested in Taveta in possession of twenty-four bundles of poison. Ife said that he visited the area regularly selling poison and on one previous trip had brought 500 packets of poison to Taveta and sold the whole lot within a month. His average load for one trip was 200 packets. On the same day another man was arrested in possession of poison. A week before he had received seventy bundles from an agent who lives at Awatate and goes into the Giriama country regularly to buy poison. He also made a good business of making bows and arrows-a bow without bow-string fetches 50 cents, arrows unpoisoned, 1s. each. A man placing an order must produce a giraffe tail for the binding of the arrows. 
Other kinds of killing.-Up to mid-October, approximately 1,700 lbs. of game meat was shot each week on Ziwani Sisal estate for labour consumption. This was shot on private land and therefore within the law, but all this game comes out of the park in order to drink at the dams or canals on the estate.

The odd buck or bird is sometimes killed near the main road by passing motorists, but such poaching is negligible when compared with the slaughter of game by Africans. In October, 1955, an Asian railway employee was fined 1,000s. for shooting an eland in the Park. Such poachers, although rare, are dealt with ruthlessly. If such ruthlessness were applied to the African, the poaching problem would be quite different.

Extent of Poaching.-I have every reason to believe that this state of affairs exists throughout the entire area, and that at certain times of the year poaching is done by the Waliangulu in the area around Kinsharo.

My report is based on only a minute portion of the Tsavo National Park, but the whole situation is extremely grave: before long, if nothing is done, it will be too late. 

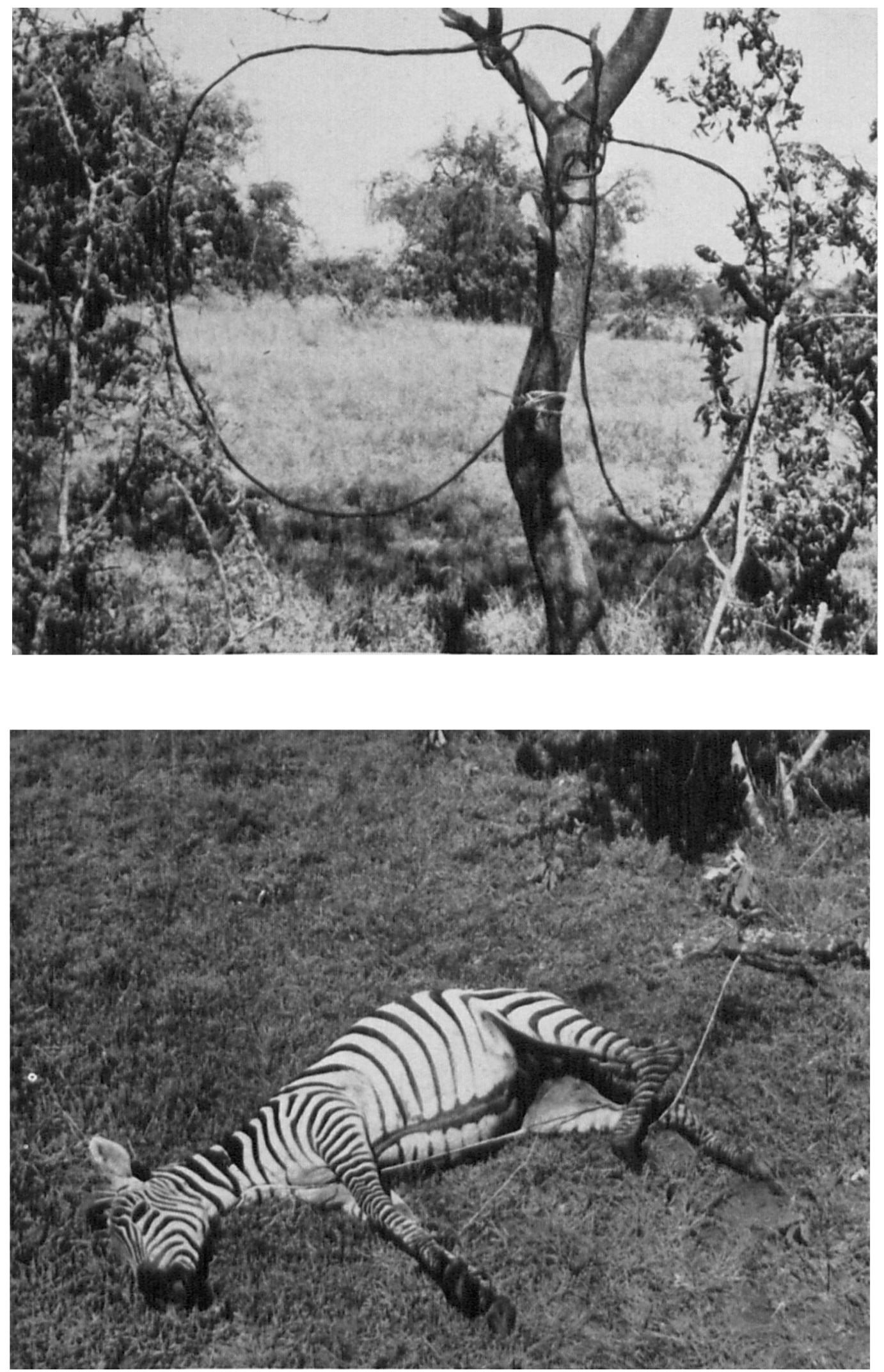

Photos: Hos Muratit Givion.

1boce : Wire smares which eatch and slowly strangle large antelopes. Belowe: Zebra trapped by African poachers. 